\title{
The effect of melatonin in functional heartburn: A randomized, placebo-controlled clinical trial
}

\author{
Patrick P. Basu ${ }^{1,2,3}$, Hemanth Hempole ${ }^{2}$, Nitya Krishnaswamy ${ }^{2}$, Niraj J. Shah ${ }^{4}$, Mark M. Aloysius ${ }^{3 *}$ \\ ${ }^{1}$ Columbia University College of Physicians and Surgeons, New York, USA \\ ${ }^{2}$ North Shore University Hospital at Forest Hills, Forest Hills, USA \\ ${ }^{3}$ King's County Hospital, New York, USA \\ ${ }^{4}$ James J. Peters VA Medical Center, Mount Sinai School of Medicine, New York, USA \\ Email: ${ }^{\text {mark.aloysius5@gmail.com }}$ \\ Received 17 November 2013; revised 25 December 2013; accepted 3 January 2014 \\ Copyright (C) 2014 Patrick P. Basu et al. This is an open access article distributed under the Creative Commons Attribution License, \\ which permits unrestricted use, distribution, and reproduction in any medium, provided the original work is properly cited. In accor- \\ dance of the Creative Commons Attribution License all Copyrights @ 2014 are reserved for SCIRP and the owner of the intellectual \\ property Patrick P. Basu et al. All Copyright (C) 2014 are guarded by law and by SCIRP as a guardian.
}

\section{ABSTRACT}

Background: Melatonin is a safe and effective treatment for patients with functional pain and gastrointestinal disorders. Objective: To evaluate the efficacy and safety of melatonin for 3 months in patients with functional heartburn. Methods: In the randomized, placebo-controlled pilot study, patients with functional heartburn were treated with omeprazole $20 \mathrm{mg}$ before breakfast and randomized to receive either melatonin $6 \mathrm{mg}(n=20)$, nortripty line $25 \mathrm{mg}(n=20)$, or placebo $(n=20)$ at bedtime for 3 months. Gastroesophageal Reflux Disease-Health-Related Quality of Life (GERD-HRQOL) scores were assessed at baseline and at the end of the study. Results: Melatonin improved GERD-HRQOL scores compared with nortriptyline $(P=0.0015)$ and placebo $(P<0.0001)$. Fewer adverse events were reported by patients receiving melatonin compared with those receiving nortriptyline or placebo. Conclusions: Melatonin was a safe and effective treatment for functional heartburn.

\section{KEYWORDS}

Melatonin; Functional Heartburn; Nortriptyline; HRQOL

\section{INTRODUCTION}

Functional heartburn is characterized by retrosternal burning without symptoms of gastroesophageal acid reflux (GERD) and the absence of esophageal motility disorders as determined by histopathology [1]. A diagnosis of

${ }^{*}$ Corresponding author. functional heartburn can be made for patients with nonerosive reflux disease (NERD) and normal 24-hour esophageal $\mathrm{pH}$ monitoring [2]. Additionally, patients with functional heartburn generally fail to respond to treatment with proton pump inhibitors [1]. Compared with patients with NERD, some patients with functional heartburn have esophageal hypersensitivity to acid and others lack sensitivity to chemical stimuli [3].

The mechanistic basis for a diagnosis of functional heartburn is currently unclear, as it is a standard treatment regimen [1]. However, novel therapeutics are under investigation and include agents that improve acid suppression, reduce the transient lower esophageal sphincter relaxation rate, decrease esophageal pain hypersensitivity, and increase esophageal motility [3]. Melatonin, a neurohormone related to serotonin [4], is synthesized in the enterochromaffin cells of the gut [5] where its release is likely dependent on food intake [6]. Melatonin acts in the gastrointestinal tract to inhibit serotonin (6) by binding to serotonin receptors [7], thereby relaxing smooth muscle [6] and increasing mucosal blood flow [8]. The effects of melatonin have been shown to occur in a dose-dependent manner [9], and its potential mechanisms of action include theabilities to scavenge free radicals and act as an antioxidant [10], reduce the secretion of hydrogen chloride [11], and stimulate the immune system by increasing the number and size of Peyer's patches (reviewed in [11]).

Melatonin has also been shown to have antinociceptive properties, and several mechanisms have been proposed to explain these effects [12]. Melatonin can act viamembrane-bound receptors through a mechanism mediated by interaction with adrenergic, dopaminergic, and serotonergic receptors $[12,13]$ as well as an interac- 
tion with opioid systems $[12,14]$. Melatonin is thought to relieve abdominal pain through its action on gut visceral hypersensitivity [15] and through its antioxidant function, which has been proposed to alleviate pain [13] by reducing the pain response to reactive oxygen species during inflammation [16]. Indeed, several studies have shown the effectiveness of melatonin in functional pain syndromes (e.g., fibromyalgia [17], migraine [17-19]) and functional gastrointestinal disorders (i.e., irritable bowel syndrome [IBS]) [15,17,20]. Abnormal endogenous melatonin concentrations have been measured in patients with IBS [20], and administration of melatonin reduced abdominal pain [15] and extracolonic symptoms [20]. Because melatonin has been effective in treating functional pain disorders and gastrointestinal dysfunction, the a priori hypothesis of this study is that melatonin will be efficacious in the treatment of functional heartburn. The aim of this randomized, placebo-controlled pilot study was to evaluate the efficacy and safety of melatonin 6 mg in patients with functional heartburn.

\section{METHODS}

\subsection{Study Design}

This study was a randomized, placebo-controlled clinical trial conducted between June 2009 and June 2010. The study protocol was approved by the North Shore-Long Island Jewish Health System Institutional Review Board and was performed in accordance with the Declaration of Helsinki, the International Conference on Harmonization Good Clinical Practice Guidelines, and applicable local laws and regulations. Signed informed consent was obtained for each patient before study enrollment.

\subsection{Patient Population}

Patients meeting Rome III criteria for functional heartburn were recruited from a community practice for gastroenterology, hepatology, liver transplant, and internal medicine. Patients were recruited from a multi-ethnic urban population. Esophageal biopsies of the antrum, body, distal, and proximal esophagus were performed as part of the diagnostic assessment for functional heartburn. In addition, patients underwent 24-hour $\mathrm{pH}$ monitoring (Restech Dx-pH Measurement System ${ }^{\mathrm{TM}}$; Respiratory Technology Corporation, San Diego, CA) and were evaluated by an ear, nose, and throat specialist for laryngeal reflux. Following recruitment into the study, all patients receiving melatonin and nortripty line and 13 patients receiving placebo underwent esophageal manometry under fasting conditions. Exclusion criteria included active ulcers, eosinophilic esophagitis, dyspepsia, achalasia, esophageal stricture, esophageal infections, scleroderma, $\mathrm{He}$ licobacter pylori gastritis, and use of drugs affecting motility.

\subsection{Treatment}

Patients received omeprazole $20 \mathrm{mg}$ before breakfast and underwent lifestyle modification, including avoidance of acid-producing food and drinks (e.g., tea, coffee, alcohol, spicy food, citrus juice, carbonated soda, peppermint, chocolate) and medications (e.g., steroids, 5-aminosalicylic acid, nonsteroidal anti-inflammatory drugs), alteration of sleep posture, weight loss, and no sleep for at least 2 hours after consumption of the last meal. Patients were randomized to receive oral placebo, nortriptyline $25 \mathrm{mg}$ (Pamelor $^{\mathrm{TM}}$; PatheonInc, Whitby, Ontario, Canada), or over-the-counter melatonin $6 \mathrm{mg}$ at bedtime for 3 months. Patients were administered study medications under the supervision of a pharmacist.

\subsection{Assessment of GERD Symptom Severity Scores}

Symptom severity was assessed at baseline and posttreatment using the GERD-Health-Related Quality of Life (GERD-HRQOL) instrument, a valid, reliable, and practical assessment of symptom severity in patients with GERD [21]. It is a questionnaire with 10 questions related to symptoms (e.g., "How bad is your heartburn?” and "Do you have pain with swallowing?") and 1 question regarding patient satisfaction (i.e., "How satisfied are you with your present condition?”). The first 10 items are scored on a scale of 0 (no symptoms) to 5 (symptoms are incapacitating; unable to do daily activities), while the patient-reported global satisfaction assessment is not scored (answers are "satisfied," “neutral,” or "dissatisfied”). Individual item scores were added to derive a total score, which ranged from 0 (asymptomatic in all items) to 50 (incapacitated in all items).

\subsection{Statistical Analysis}

The $t$ test was used to compare differences in GERDHRQOL scores across treatment groups.

\section{RESULTS}

\subsection{Patients and Baseline Characteristics}

A total of 60 patients were enrolled in the study. Twenty patients were randomized into each treatment arm: melatonin $6 \mathrm{mg}$, nortripty line $25 \mathrm{mg}$, and placebo. The characteristics of the patients in each group were similar with respect to age, sex, race, and body mass index (Table 1).

\subsection{Diagnosis of Functional Heartburn}

Biopsies of the distal esophagus taken $2 \mathrm{~cm}$ above the gastroesophageal junction underwent special stains for histological analysis as a diagnostic tool for functional 
Table 1. Patient baseline characteristics.

\begin{tabular}{cccc}
\hline & $\begin{array}{c}\text { Melatonin } \\
\mathbf{6} \mathbf{~ m g} \\
(\mathbf{n = 2 0})\end{array}$ & $\begin{array}{c}\text { Nortriptyline } \\
\mathbf{2 5} \mathbf{~ m g} \\
(\mathbf{n}=\mathbf{2 0})\end{array}$ & $\begin{array}{c}\text { Placebo } \\
(\boldsymbol{n}=\mathbf{2 0})\end{array}$ \\
\hline Age, mean \pm SD, y & $34 \pm 9$ & $37 \pm 9$ & $35 \pm 9$ \\
Male:Female & $10: 10$ & $9: 11$ & $8: 12$ \\
Race, $\mathrm{n}$ & & & \\
White & 7 & 7 & 7 \\
Hispanic & 9 & 10 & 8 \\
$\begin{array}{c}\text { Black } \\
\text { Asian }\end{array}$ & 3 & 2 & 4 \\
BMI, mean \pm SD, & 1 & 1 & 1 \\
$\mathrm{~kg} / \mathrm{m}^{2}$ & $27 \pm 4$ & $28 \pm 5$ & $28 \pm 4$ \\
\hline
\end{tabular}

BMI, body mass index; SD, standard deviation.

heartburn. The dilated intracellular space, pathognomonic for reflux esophagitis, was within normal limits. Eosinophil counts were $<5 /$ high-power field (hpf) in 5 of 60 patients (8\%), indicating these patients were negative for a diagnosis of eosinophilic esophagitis. Mast cell countsto verify the existence of histamine-releasing mast cells were $<10 /$ hpf in 11 of 60 patients (18\%). Interleukin-5 immunostainingas a screen for eosinophilic prevalence was negative.

\subsection{Improvement in Heartburn Symptoms}

The GERD-HRQOL assessment instrument was used to assess improvement in heartburn symptoms following treatment (Table 2 \& Figure 1). A significantly greater percentage of patients receiving melatonin $6 \mathrm{mg}$ (75\%) reported improvement in heartburn symptoms than patients receiving nortriptyline $25 \mathrm{mg}$ (20\%; $P=0.0015)$. The percentage of patients with improvement in GERDHRQOL score was also greater with melatonin than placebo $(45 \%$; $P<0.0001)$. Nortriptyline resulted in the fewest number of patients reporting relief of their heartburn symptoms, and the difference was significant when compared with placebo $(P<0.0001)$.

While baseline GERD-HRQOL scores were similar across the 3 treatment groups, GERD-HRQOL post treatment scores differed significantly between treatment groups. Melatonin treatment resulted in the lowest mean post treatment GERD-HRQOL score (13 points), which was significantly less than the mean post treatment GERDHRQOL score for patients treated with nortriptyline (17 points; $P=0.0015$ ) or placebo (20 points; $P<0.0001$ ). Treatment with nortriptyline also resulted in a significantly lower mean posttreatment GERD-HRQOL score compared with placebo $(P<0.0001)$.

\subsection{Adverse Events}

Patients in the melatonin group reported better tolerability and fewer total adverse events than those in the nor-
Table 2. Mean GERD-HRQOL ${ }^{\mathrm{a}}$ baseline and post treatment scores in patients with functional heartburn.

\begin{tabular}{cccc}
\hline & $\begin{array}{c}\text { Baseline } \\
\text { score }\end{array}$ & $\begin{array}{c}\text { Post treatment } \\
\text { score }\end{array}$ & Difference $^{\mathrm{b}}$ \\
\hline $\begin{array}{c}\text { Melatonin } 6 \mathrm{mg} \\
(n=20)\end{array}$ & 27 & $13^{\mathrm{c}, \mathrm{d}}$ & 14 \\
$\begin{array}{c}\text { Nortriptyline } \\
25 \mathrm{mg}(n=20) \\
\begin{array}{c}\text { Placebo } \\
(n=20)\end{array}\end{array}$ & 26 & $17^{\mathrm{d}}$ & 9 \\
\hline
\end{tabular}

GERD-HRQOL, Gastroesophageal Reflux Disease-Health-Related Quality of Life. ${ }^{\mathrm{a}}$ Scores rated from 0 (no symptoms) to 5 (symptoms are incapacitating; unable to do daily activities) for 10 different items, and scores are added to calculate the GERD-HRQOL score. The total score ranges from 0 (asymptomatic in all items) to 50 (incapacitated in all items). ${ }^{\mathrm{b}}$ Difference between posttreatment and baseline scores. ${ }^{\mathrm{c}} P=0.0015$ vs. nortriptyline. ${ }^{\mathrm{d}} P$ $<0.0001$ vs. placebo.

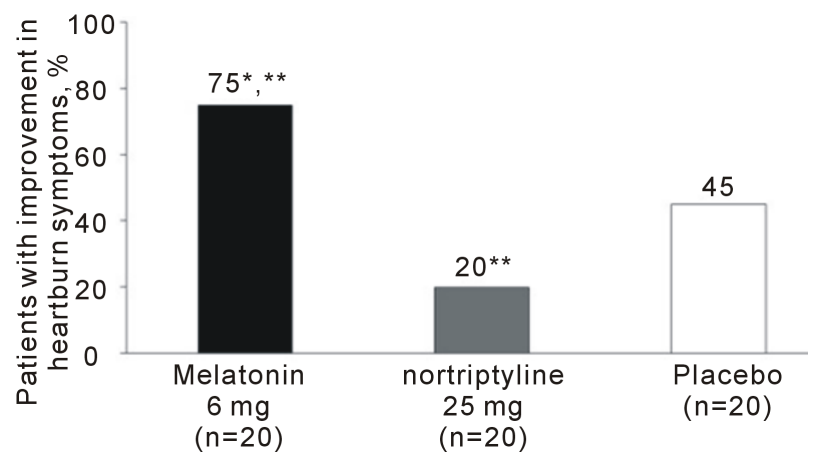

Figure 1. Percentage of patients with improvement in heartburn symptoms as assessed using Gastroesophageal Reflux Disease-Health-Related Quality of Life. Symptom severity instrument. ${ }^{*} P=0.0015$ vs. nortriptyline. ${ }^{* *} P<0.0001$ vs. placebo.

triptyline or placebo groups (Table 3). A similar percentage of patients receiving melatonin (25\%) or placebo (30\%) reported abdominal distention compared with patients receiving nortriptyline ( $0 \%)$. Diarrhea was reported by $20 \%$ of patients receiving melatonin but not by those receiving nortriptyline or placebo. Fewer patients receiving melatonin $(20 \%)$ reported daytime somnolence compared with patients receiving nortriptyline $(45 \%)$ or placebo (55\%). No patients receiving melatonin or placebo reported dry mouth, yet more than half of patients receiving nortriptyline (55\%) did. No patients in the melatonin group reported constipation, but this adverse event was reported in $35 \%$ of patients receiving nortriptyline and $25 \%$ of patients receiving placebo.

\section{DISCUSSION}

The results of this randomized, placebo-controlled clinical trial suggest that melatonin improves symptoms compared with nortriptyline or placebo in patients with functional heartburn who were receiving concomitant omeprazole. This study is the first to show a role for me 
Table 3. Adverse events.

\begin{tabular}{|c|c|c|c|}
\hline & \multicolumn{3}{|c|}{ Patients, n (\%) } \\
\hline & $\begin{array}{c}\text { Melatonin } \\
\quad 6 \mathrm{mg} \\
(n=20)\end{array}$ & $\begin{array}{c}\text { Nortriptyline } \\
25 \mathrm{mg} \\
(n=20)\end{array}$ & $\begin{array}{l}\text { Placebo } \\
(n=20)\end{array}$ \\
\hline Daytime somnolence & $4(20)$ & $9(45)$ & $11(55)$ \\
\hline Abdominal distention & $5(25)$ & $0(0)$ & $6(30)$ \\
\hline Constipation & $0(0)$ & $7(35)$ & $5(25)$ \\
\hline Diarrhea & $4(20)$ & $0(0)$ & $0(0)$ \\
\hline Dry mouth & $0(0)$ & $11(55)$ & $0(0)$ \\
\hline
\end{tabular}

latonin as therapy in patients with functional heartburn and adds to the body of literature demonstrating the efficacy of melatonin in treating functional gastrointestinal disorders (e.g., IBS [15,17,20] and GERD [22,23]) and functional pain disorders (e.g., migraine [17-19] and fibromyalgia [17]). These findings relating to relief of heartburn symptoms by melatonin are similar to previous reports in the literature on GERD and melatonin [22,23].

In a study of patients with GERD, a supplement containing melatonin $6 \mathrm{mg}$ was compared with omeprazole $20 \mathrm{mg}$ in a single-blind, randomized study [23]. All patients reported a complete regression of symptoms (i.e., heartburn, regurgitation, belching, early satiety, bloating, nausea, and vomiting) following treatment with the supplement for 40 days, compared with $65.7 \%$ of patients receiving omeprazole $20 \mathrm{mg}(P<0.05)$. At the end of the study, patients enrolled in the omeprazole arm of the study who still reported symptoms of GERD received the melatonin-containing supplement for 40 days. At the end of the treatment period, $100 \%$ of these patients reported a complete regression of symptoms. The finding of this study of GERD with heartburn as a symptom is comparable to the current study of functional heartburn in that both patient groups were concomitantly treated with omeprazole and melatonin $6 \mathrm{mg}$, albeit in different forms or for different lengths of time. In another study of patients with GERD, melatonin effectively resolved symptoms of heartburn in $100 \%$ of patients and epigastric pain symptoms in $83 \%$ of patients [22]. Additionally, melatonin significantly decreased basal acid output relative to baseline. Taken together, these findings suggest that melatonin may be effective for relief of symptoms of heartburn regardless of associated conditions (i.e., GERD or functional heartburn).

This study compares the efficacy of melatonin with placebo and nortriptyline, a tricyclic antidepressant. Antidepressants like nortriptyline have been used to treat pain disorders like fibromyalgia [24] and migraine [25], but their use in the treatment of functional heartburn has not yet been reported. However, studies have demonstrated that antidepressants used at a subtherapeutic dose for the treatment of depression relieve pain in patients with functional gastrointestinal disorders [26,27]. In this study, nortriptyline was more effective than placebo, but not melatonin, in reducing the GERD-HRQOL score but did not result in an increased percentage of patients with symptom relief. This result suggests that nortriptyline may be particularly effective in a certain subset of patients with functional heartburn.

One limitation of this study was that it was small in size $(N=60)$. Furthermore, patients underwent lifestyle modifications, and all treatment groups were receiving concomitant omeprazole. The finding that there was improvement in the symptom severity score in the placebo group, though small, suggests that omeprazole and lifestyle modifications could have played a role in this study. However, the improvement seen with melatonin was significantly greater than that seen with placebo, indicating that the effect was most likely due to melatonin. A second limitation of this study is that a single dose of melatonin was examined. It is possible that a higher dose or longer treatment duration may lead to adverse events in some patients that may not have been observed in this study. While adverse events were minimal, they were reported in the melatonin treatment arm. It is also possible that in some individuals, melatonin $6 \mathrm{mg}$ is not an optimal dose for treating functional heartburn, especially because melatonin has been reported to act in a dose-dependent manner $[9,28]$. Additionally, this study was performed at a single institution in New York, and the results may not fully extend to patient groups in other parts of the country or world, especially since melatonin is involved in signaling the time of day and year to the human body [29]. Finally, because the GERD-HRQOL symptom severity instrument is only considered a reliable tool for assessing symptom severity in patients with functional heartburn $[21,30]$, this study cannot draw conclusions on whether melatonin affects patients' overall quality of life.

In this study, melatonin was safe and well tolerated in patients with functional heartburn. Patients who received melatonin treatment reported less daytime somnolence, which was not a surprising finding because melatonin is a pharmacologic intervention used to treat various sleep disorders (e.g., jet lag disorder, shift work sleep disorder, irregular sleep-wake rhythm) [31]. Diarrhea was also reported by patients treated with melatonin in this study, which was not an unexpected result based on the findings of a previous report [32]. Patients treated with melatonin also had better tolerability with respect to abdominal distention, constipation, and dry mouth. The favorable safety and tolerability profile reported by patients receiving melatonin correlates with findings from other studies in different patient populations [19,32,33].

\section{CONCLUSION}

In conclusion, while performed in a small group of patients, this randomized, placebo-controlled pilot study 
demonstrates that melatonin is safe and effective for alleviating symptoms in patients with functional heartburn. Large, randomized clinical trials are needed to fully assess the efficacy and safety of melatonin in patients with functional heartburn. Due to the dose-dependent antioxidant effect of melatonin [9,28], a trial comparing multiple doses of melatonin would be particularly beneficial.

\section{SPECIFIC AUTHOR CONTRIBUTIONS}

Niraj J. Shah, Hemanth Hempole, Nitya Krishnaswamy were involved with planning and/or conducting the study, collecting and/or interpreting data and in drafting the manuscript.

P. Patrick Basu has approved the final draft submitted.

Mark $M$ Aloysiuswas involved with writing and final approval of the final draft submitted.

\section{FINANCIAL SUPPORT}

Editorial assistance was provided under the direction of the authors by Med Think Communications with support from Salix Pharmaceuticals, Inc.

\section{POTENTIAL COMPETING INTERESTS}

None.

\section{STUDY HIGHLIGHTS}

1) What Is Current Knowledge

- Melatonin has been shown to be effective in patients with functional gastrointestinal and pain disorders.

- There is no standard treatment for patients with functional heartburn, and most patients do not respond to treatment with proton pump inhibitors.

2) What is New Here

- Melatonin is safe and effective in patients with functional heartburn.

- Treatment with melatonin significantly improves symptoms of heartburn and health-related quality of life scores compared with placebo or nortriptyline in patients with functional heartburn.

\section{REFERENCES}

[1] Galmiche, J.P., Clouse, R.E., Balint, A., Cook, I.J., Kahrilas, P.J., Paterson, W.G., et al. (2006) Functional esophageal disorders. Gastroenterology, 130, 1459-1465.

[2] Martinez, S.D., Malagon, I.B., Garewal, H.S., Cui, H. and Fass, R. (2003) Non-erosive reflux disease (NERD)-acid reflux and symptom patterns. Alimentary Pharmacology \& Therapeutics, 17, 537-545.

[3] Hershcovici, T. and Fass, R. (2010) Nonerosive Reflux Disease (NERD) - An update. Journal of Neurogastroenterology and Motility, 16, 8-21.

[4] Lu, W.Z., Song, G.H., Gwee, K.A. and Ho, K.Y. (2008)
The effects of melatonin on colonic transit time in normal controls and IBS patients. Digestive Diseases Sciences, 54, 1087-1093.

[5] Raikhlin, N.T. and Kvetnoy, I.M. (1976) Melatonin and enterochromaffine cells. Acta Histochemica, 55, 19-24.

[6] Bubenik, G.A. (2008) Thirty four years since the discovery of gastrointestinal melatonin. Journal of Physiology and Pharmacology, 59, 33-51.

[7] Kasimay, O., Cakir, B., Devseren, E. and Yegen, B.C. (2005) Exogenous melatonin delays gastric emptying rate in rats: Role of CCK2 and 5-HT3 receptors. Journal of Physiology and Pharmacology, 56, 543-553.

[8] Cho, C.H., Pang, S.F., Chen, B.W. and Pfeiffer, C.J. (1989) Modulating action of melatonin on serotonin-induced aggravation of ethanol ulceration and changes of mucosal blood flow in rat stomachs. Journal of Pineal Research, $\mathbf{6}$, 89-97.

[9] Kato, K., Murai, I., Asai, S., Komuro, S., Matsuno, Y., Ma-tsukawa, Y., et al. (1997) Central effect of melatonin against stress-induced gastric ulcers in rats. Neuroreport, 8, 2305-2309.

[10] Pieri, C., Marra, M., Moroni, F., Recchioni, R. and Marcheselli, F. (1994) Melatonin: A peroxyl radical scavenger more effective than vitamin E. Life Science, 55, PL271-PL276.

[11] Bubenik, G.A. (2002) Gastrointestinal melatonin: Localization, function, and clinical relevance. Digestive Diseases Sciences, 47, 2336-2348.

[12] Mantovani, M., Kaster, M.P., Pertile, R., Calixto, J.B., Rodrigues, A.L. and Santos, A.R. (2006) Mechanisms involved in the antinociception caused by melatonin in mice. Journal of Pineal Research, 41, 382-389.

[13] Ray, M., Mediratta, P.K., Mahajan, P. and Sharma, K.K. (2004) Evaluation of the role of melatonin in formalininduced pain response in mice. Indian Journal of Medical Sciences, 58, 122-130.

[14] Mickle, A., Sood, M., Zhang, Z., Shahmohammadi, G., Sengupta, J.N. and Miranda, A. (2010) Antinociceptive effects of melatonin in a rat model of post-inflammatory visceral hyperalgesia: A centrally mediated process. Pain, 149, 555-564.

[15] Song, G.H., Leng, P.H., Gwee, K.A., Moochhala, S.M. and Ho, K.Y. (2005) Melatonin improves abdominal pain in irritable bowel syndrome patients who have sleep disturbances: A randomised, double blind, placebo controlled study. Gut, 54, 1402-1407.

[16] Esposito, E., Paterniti, I., Mazzon, E., Bramanti, P. and Cuzzocrea, S. (2010) Melatonin reduces hyperalgesia associated with inflammation. Journal of Pineal Research, 49, 321-331.

[17] Wilhelmsen, M., Amirian, I., Reiter, R.J., Rosenberg, J. and Gogenur, I. (2011) Analgesic effects of melatonin: A review of current evidence from experimental and clinical studies. Journal of Pineal Research, 51, 270-277.

[18] Ambriz-Tututi, M., Rocha-Gonzalez, H.I., Cruz, S.L. and Granados-Soto, V. (2009) Melatonin: A hormone that modulates pain. Life Science, 84, 489-498.

[19] Gagnier, J.J. (2001) The therapeutic potential of melato- 
nin in migraines and other headache types. Alternative Medicine Review, 6, 383-389.

[20] Mozaffari, S., Rahimi, R. and Abdollahi, M. (2010) Implications of melatonin therapy in irritable bowel syndrome: A systematic review. Current Pharmaceutical Design, 16, 3646-3655.

[21] Velanovich, V. (2007) The development of the GERDHRQL symptom severity instrument. Diseases of the Esophagus, 20, 130-134.

[22] Kandil, T.S., Mousa, A.A., El-Gendy, A.A. and Abbas, A.M. (2010) The potential therapeutic effect of melatonin in gastro-esophageal reflux disease. BMC Gastroenterology, 10, 7.

[23] Pereira Rde, S. (2006) Regression of gastroesophageal reflux disease symptoms using dietary supplementation with melatonin, vitamins and aminoacids: Comparison with omeprazole. Journal of Pineal Research, 41, 195-200.

[24] Smith, B., Peterson, K., Fu, R., McDonagh, M. and Thakurta, S. (2011) Drug class review: Drugs for fibromyalgia: Final original report [Internet]. Oregon Health \& Science University, Portland, 2011.

[25] Jackson, J.L., Shimeall, W., Sessums, L., Dezee, K.J., Becher, D., Diemer, M., et al. (2010) Tricyclic antidepressants and headaches: Systematic review and metaanalysis. BMJ, 341, c5222.

[26] Jackson, J.L., O’Malley, P.G., Tomkins, G., Balden, E., Santoro, J. and Kroenke, K. (2000) Treatment of functional gastrointestinal disorders with antidepressant medications: A meta-analysis. American Journal of Medicine, 108, 65-72.
[27] Olden, K.W. (2005) The use of antidepressants in functional gastrointestinal disorders: New uses for old drugs. CNS Spectrums, 10, 891-896.

[28] Chakravarty, S. and Rizvi, S.I. (2011) Day and night GSH and MDA levels in healthy adults and effects of different doses of melatonin on these parameters. International Journal of Cell Biology, 2011, 404591.

[29] Pandi-Perumal, S.R., Srinivasan, V., Maestroni, G.J., Cardinali, D.P., Poeggeler, B. and Hardeland, R. (2006) Melatonin: Nature's most versatile biological signal? Febs Journal, 273, 2813-2838.

[30] Chassany, O., Holtmann, G., Malagelada, J., Gebauer, U., Doerfler, H. and Devault, K. (2008) Systematic review: Health-related quality of life (HRQOL) questionnaires in gastro-oesophageal reflux disease. Alimentary Pharmacology \& Therapeutics, 27, 1053-1070.

[31] Barion, A. and Zee, P.C. (2007) A clinical approach to circadian rhythm sleep disorders. Sleep Medicine, 8, 566577.

[32] Wade, A.G., Ford, I., Crawford, G., McConnachie, A., Nir, T., Laudon, M., et al. (2010) Nightly treatment of primary insomnia with prolonged release melatonin for 6 months: A randomized placebo controlled trial on age and endogenous melatonin as predictors of efficacy and safety. BMC Medicine, 8, 51.

[33] Zhdanova, I.V., Wurtman, R.J., Regan, M.M., Taylor, J.A., Shi, J.P. and Leclair, O.U. (2001) Melatonin treatment for age-related insomnia. The Journal of Clinical Endocrinology and Metabolism, 86, 4727-4730. 